\title{
Do conspicuous consumers pay higher housing premiums? Spatial and temporal variation in the United States
}

Article

Accepted Version

Lee, K. O. and Mori, M. (2016) Do conspicuous consumers pay higher housing premiums? Spatial and temporal variation in the United States. Real Estate Economics, 44 (3). pp. 726763. ISSN 1540-6229 doi: https://doi.org/10.1111/15406229.12115 Available at https://centaur.reading.ac.uk/79271/

It is advisable to refer to the publisher's version if you intend to cite from the work. See Guidance on citing.

To link to this article DOI: http://dx.doi.org/10.1111/1540-6229.12115

Publisher: American Real Estate and Urban Economics Association

All outputs in CentAUR are protected by Intellectual Property Rights law, including copyright law. Copyright and IPR is retained by the creators or other copyright holders. Terms and conditions for use of this material are defined in the End User Agreement.

$\underline{\text { www.reading.ac.uk/centaur }}$ 
Central Archive at the University of Reading

Reading's research outputs online 


\title{
Do Conspicuous Consumers Pay Higher Housing Premiums?: Spatial and Temporal Variation in the U.S.
}

\begin{abstract}
This study is the first to examine the relationship between conspicuous demand and housing price dynamics. We hypothesize that conspicuous consumers would want high-end homes to signal their wealth and this housing consumption behavior would induce greater deviations from fundamental house prices. We test this by using a unique dataset that matches the consumers' appetite for non-housing luxury goods from Google Insights for Search to housing premiums that they pay for high-end houses in US Metropolitan Statistical Areas (MSAs) during 2004-2011. The estimation results demonstrate that controlling for a wide range of MSA demographic and economic characteristics, conspicuous demand has a significant, positive relationship with housing premiums. This relationship varies spatially and temporally. Conspicuous demand has a stronger relationship with a price increase in high-end homes in MSAs with a steady, higher housing premium than in MSAs with a volatile, lower premium during the boom period. In the MSAs with a steady, higher housing premium, the relationship remains significant even during the bust period, potentially contributing to maintaining higher housing premiums.
\end{abstract}

Keywords: Conspicuous consumption, housing market dynamics, luxury housing, housing premium, housing cycle 


\section{Do Conspicuous Consumers Pay Higher Housing Premiums?: Spatial and Temporal Variation in the U.S.}

\section{Introduction}

Some consumers are motivated to consume highly conspicuous goods and services in order to flaunt their wealth, thereby achieving greater social status (Veblen 1899). Wealthy individuals consume luxury goods even at higher prices than their intrinsic values, and luxury brands earn strictly positive profits when there is a significant demand for conspicuous consumption (conspicuous demand) in the society (Bagwell and Bernheim 1996, Corneo and Jeanne 1997). If certain types of homes are more visible in terms of size, design, and location, consumers may purchase these homes not only for the pleasure of their intrinsic value (e.g., the pleasure of living in a spacious home with excellent neighborhood amenities), but also for additional enjoyment by signaling their own wealth. Therefore, it is plausible that housing consumption is partly motivated by conspicuous demand. Especially given that such consumption behaviors lead the prices of goods to deviate from their fundamental values (Bagwell and Bernheim 1996), conspicuous demand may be associated with housing price dynamics and housing bubble (Stiglitz 1990, Case and Shiller 2004).

This study is the first to investigate a potential relationship between conspicuous demand and housing price dynamics. Specifically, we examine the relationship between consumers' appetite for non-housing luxury goods such as fashion, watches, and cars and the premium that they pay for high-end houses in US Metropolitan Statistical Areas (MSAs) during the time period of 2004-2011. We hypothesize that there would be a positive relationship between them because housing consumption motivated by conspicuous demand is likely to induce greater deviations from fundamental house prices. Then, we explore temporal variation in the relationship between 
conspicuous demand and housing premiums. By doing so, we attempt to report whether housing consumption behavior driven by conspicuous demand influences housing premiums differently during the boom and bust periods. Finally, we are able to identify why housing markets are more conspicuous in certain MSAs than others by investigating spatial variation in the relationship between conspicuous demand and housing premiums across the MSAs.

We propose a novel and direct measure of consumers' appetite for conspicuous luxury goods such as fashion, watches, and cars, utilizing unique data available through Google Insights for Search. As a measure of possible manifestation of conspicuous demand in housing markets, we use the data from Dataquick that were based on property-level transactions in each MSA and calculate price deviations of high-end houses (i.e. highest decile price) from the median price at the MSA level. To account for other MSA characteristics that could influence housing price dynamics, we include a wide range of controls such as demographics (population, median age, and median household size), housing market conditions (new construction, price composition of new housing stock, and tenure composition of high-end homes), median household income and income distribution, and the degree of racial segregation. For the statistical estimation, we use the dynamic panel system GMM regressions to address the concern of serial correlation.

The estimation results demonstrate that even after controlling for MSA demographic and economic characteristics, general demand for high-end goods, and serial correlation, conspicuous demand, which is measured by consumers' desire for non-housing luxury goods, has a significant, positive association with a premium paid in the housing markets. This suggests that high-end houses located in the MSAs with higher conspicuous demand may be purchased for the 
enjoyment of signaling wealth and status rather than for the intrinsic values of these houses. Hence, this housing consumption behavior could partly drive the large deviation of high-end house prices from the median house price. Also evident is that conspicuous demand has a stronger relationship with a price increase in high-end homes in MSAs with a steady, higher housing premium than in MSAs with a volatile, lower premium during the boom period. In MSAs with a steady, higher housing premium, the relationship remains significant even during the bust period, potentially contributing to maintaining higher housing premiums.

\section{Background and Theory}

Past research on conspicuous consumption has primarily focused on the consumption of nonhousing luxury goods. The finance literature suggests that luxury consumption behavior could be translated into consumers' behavior with other goods and assets. There is also evidence that conspicuous demand varies over time and across geographic areas. Much less well-known is if and how conspicuous demand influences housing consumption. Several recent studies suggest that housing consumption is partly motivated by behaviors associated with conspicuous demand. This study advances previous research by using the direct measures of conspicuous demand. Since we use the nation-wide panel sample of MSAs, we are also able to examine spatial and temporal variation in the relationship between conspicuous demand and housing price dynamics.

\section{The Role of Conspicuous Demand in Consumer Behavior}

Chao and Schor (1998) suggest evidence of consumption motivated to achieve higher status in the case of woman's cosmetic products. They also report a low price/quality correlation with the visible status cosmetic products, consistent with the prediction by the theory of conspicuous 
consumption (Veblen 1899). More recently, Shukla (2008), focusing on middle-aged consumers of the ages between 40-60, finds evidence of conspicuous automobile consumption motivated mostly to signal symbols of prestige and success and enhanced self-image. There is much anecdotal evidence of conspicuous demand based on consumer behaviors associated with luxury brands. For example, the French fashion brand Chanel has raised the prices of its popular handbag lines by 20 to 30 percent per year for the last several years in most countries, yet consumers buy its products under any circumstances (The Chosunilbo 20 January, 2012). In the same newspaper article, a fashion industry insider said, "customers spend recklessly due to their label addiction".

The finance literature suggests that conspicuous demand may also affect consumers' behavior with goods/assets other than luxury goods. Ait-Sahalia et al. (2004) and Hiraki et al. (2009) report that the risk aversion implied by luxury consumption rather than by basic consumption is more consistent with the observed equity premium and suggest a potential link between stock investors' behavior and conspicuous demand evident in luxury consumption. ${ }^{1}$ Mandel (2009) argues that the determinants of an artwork's value are distinct from equities and other investments, because owning art, especially a masterpiece, is considered to be luxury consumption as well as an investment, with which owners signal their wealth. The author then concludes that, once the luxury consumption nature of art is accounted for in a consumptionbased pricing model, the very low observed returns on art investments are justified.

\footnotetext{
${ }^{1}$ These studies effectively show that the inclusion of luxury consumption in the consumption CAPM framework largely solves the equity premium puzzle that the risk of the stock market as measured by its co-movement with aggregate consumption is insufficient to justify the extent to which its average return exceeds the return on shortterm government debt.
} 
Spatial and Temporal Variation in Conspicuous Demand across MSAs

Some studies suggest the importance of spatial and temporal variation of conspicuous demand. Veblen (1899) suggests that the degree of demand for conspicuous consumption should differ across different areas, arguing that consumption behaviors that signal wealth are more evident in communities where human contact for consumers is wider and the mobility of the population is greater. Furthermore, Ferreira and Gyourko (2011) argue that the start of the housing boom during the period between 1993 and 2009 was not a single national event; rather, the housing boom started at different times at different degrees across 94 MSAs. Thus, the examination of the potential role of conspicuous demand and its spatial and temporal variation would provide important insights into the reasons behind different housing cycles of boom and bust across different housing markets in the U.S.

\section{The Role of Conspicuous Demand in Housing Consumption}

Much less well-known is how conspicuous demand can influence housing consumption behaviors. Existing evidence is mixed and fragmentary. Using the data on 80,000 property transactions for six MSAs in Ohio for the year 2000, Leguizamon (2010) finds that individuals prefer to have a house larger than their nearest neighbor and live in a district with a smaller difference between their own house size and that of the largest houses in the district. ZahirovicHerbert and Chatterjee (2011) provide empirical supports that real property buyers, especially wealthier buyers, pay price premiums for conspicuous property names such as those containing the phrase "country club." Both Leguizamon (2010) and Zahirovic-Herbert and Chatterjee (2011) suggest the possible effect of conspicuous demand on house prices. While using the similar framework to Leguizamon (2010), however, Turnbull et al. (2006) find no evidence of 
the association between conspicuous demand and house prices. They rely on the data of 2,111 property transactions in East Baton Rouge Parish, Louisiana, during the period of January 1992 through September 1997.

\section{Other Potential Reasons to Pay Higher Premium for Housing in Certain MSAs}

Households residing in certain MSAs and/or in certain years may pay higher housing premiums because of other reasons than the conspicuous desire for high-end homes. Several housing market conditions in MSAs are closely related with both supply and demand for high-end homes, and in turn, may influence housing premiums. ${ }^{2}$ First, new housing construction indicates supply elasticity in a given housing market. We measure this with the number of building permits and annual percentage change of the number of permits. Second, the price composition of new housing stock (i.e. number of high-end houses vs. number of houses in the middle price range) may further influence the level of median house price as well as housing premiums paid for highend houses. For example, MSAs concentrated with the supply of higher-end homes would lead to higher median house price and lower housing premiums. We use the MSA-specific price composition of new single-family houses that are sold in a given year. Finally, the tenure composition of high-end homes may also matter for housing premiums. If the volume of highend rental units is high relative to the volume of high-end owner-occupied units in certain MSAs, ${ }^{3}$ conspicuous households may choose renting instead of owning high-end homes. Thus,

\footnotetext{
${ }^{2}$ In addition to variables considered in this analysis, mortgage market circumstances could be an important factor affecting variation in the housing premium across different MSAs. Among housing market conditions that we consider, some of them are closely related to mortgage market characteristics. For example, the number of building permits and change in permits would reflect any additional demand caused by subprime loans. If subprime loan holders contributed to a new purchase of high-end homes, this would have already been accounted for in our variable of the price composition of new housing stock.

${ }^{3}$ For example, those in New York may have abundant options of luxury rental units while those in Dallas may not have these options and end up in the sales housing markets.
} 
the availability of high-end rental units may weaken the relationship between conspicuous demand and housing premiums.

Higher variation in demographics across neighborhoods within a MSA could also lead households who are sensitive to the attributes of surrounding neighbors to pay higher housing premiums. As Cutler et al. (1999) demonstrate, White households residing in more segregated MSAs tend to pay higher premium for equivalent housing than blacks to collectively exclude Blacks from their neighborhoods. Research on White flight suggests that White households may wish to avoid predominantly black neighborhoods by paying a higher premium for housing (Crowder 2000). On the other hand, if neighborhoods within a MSA are relatively homogenous in terms of racial composition, households may be indifferent to the choice of neighborhoods. We use the dissimilarity index from Census to control for the level of demographic homogeneity in the MSAs.

Finally, households residing in different MSAs may have different abilities to pay housing premiums during the boom period as well as to avoid the default risk from higher cost housing during the bust period. These abilities would be associated with the strength of MSA's economy which we control for using median household income. In addition, non-conspicuous demand for high-end goods may vary across MSAs. We account for this by including the income distribution of MSAs in our statistical models. 


\section{Data and Methodology}

We utilized a unique dataset available through Google Insights for Search to extract consumers' appetite for luxury goods as a measure of their desire to signal their wealth (conspicuous demand). Google's tool, Google Insights for Search, ${ }^{4}$ contains the Search Volume Index (SVI) of search keywords. Weekly SVI for a search keyword is the number of searches for that keyword, relative to the total number of searches done on Google over time. Data since the year 2004 is available by country, by state, and by MSA. Google search is considered a good representative of Internet search behavior among the general population. In particular, Google accounted for $65.3 \%$ of all search queries performed in the U.S. during the month of September 2011.5 More importantly, Internet search is a revealed attention measure, thus it can be a direct measure of a variety of economic activities in real time. For example, Choi and Varian (2012) show that the Google search volume is helpful in predicting near-term automobile sales, unemployment claims, travel destination planning, and consumer confidence. Da et al. (2011) further validate the information quality of Google search volume data as a direct measure of consumers' interest/attention. The authors use the Google's SVI as a direct measure of investors' attention. Utilizing the SVI for stock ticker symbols, they showed that SVI captures the attention of investors (especially of retail investors) in a timely fashion and that an increase in SVI predicts higher stock prices over the following two weeks and an eventual price reversal within the year. They also find the significant relationship between SVI and the large first-day return of IPO stocks.

\footnotetext{
${ }^{4}$ This service is now called, Google Trends

${ }^{5}$ Source: http://technolog.msnbc.msn.com/_news/2011/10/12/8289269-google-holds-steady-with-65-percent-of-ussearch-queries
} 
We propose a novel measure of consumers' appetite for luxury goods by calculating the proportion of SVI for luxury brand names to SVI for the name of a product. For example, we collected the SVI for "car" (product SVI) and SVIs for luxury car brands such as "BMW," "Mercedes," "Jaguar," and "Porsche" (brand SVI). We calculated the proportion of the aggregated brand SVI to the product SVI. Through this process, we measure consumers' appetite specifically for goods that are significantly conspicuous, controlling for their general appetite for a product, and use it as a proxy for conspicuous demand. To additionally measure consumers' appetite for luxury goods in other products, we applied the same method to product categories of "Fashion and Leather", "Watches and Jewelry", and "Cosmetics and Perfume", with SVIs for respective luxury brands that offer these products. Appendix A explains a detailed description of category selection and luxury brand selection process and shows the list of luxury brand key words for four product categories (Table A). The SVI data are available from 2004 on a weekly basis at the MSA level (185 MSAs), and we converted weekly data to quarterly data.

To match these data with the possible manifestation of conspicuous demand in housing markets, we obtained information from Dataquick, which covers $85 \%$ of all U.S. residences and $90 \%$ of all sale and loan transactions. We obtained quarterly data of the median home price and the highest decile home price in each MSA that were based on property-level transactions from 2004 to 2011. With this information, we calculated the difference between the highest decile and the median, which indicates housing premiums that homebuyers in each MSA pay for the high-end homes, potentially motivated by conspicuous demand. Our dependent variable is these housing premiums in each MSA and in each quarter. To test whether this possible manifestation of conspicuous demand in housing markets is associated with conspicuous demand, our main 
independent variable is the ratio of brand SVI to product SVI, as explained earlier. While using a series of ratios based on four different product types, we present main results with the automobile category. We use the quarterly data for both the dependent variable and the main independent variables.

To account for other factors that could potentially influence variation in the housing premium, we include a wide range of MSA-level control variables. First, we control for fundamental demographic characteristics such as population, median age, and median household size. Second, we account for several housing market conditions such as the proportion of houses built after 2000 , the number and the annual change of building permits (single-family), the ratio of the number of new single-family houses sold in the top $10 \%$ price range to those sold in the median price range, ${ }^{6}$ and the ratio of the number of rental units with contract rent above $\$ 1,500$ to the number of owner-occupied units with price above $\$ 1,000,000 .{ }^{7}$ Third, the dissimilarity indices (Black-White and Asian-White) are added to control potential effects of segregation/integration on the house price premium. Fourth, we include median household income to control for the ability to pay for luxury goods. Finally, households in some MSAs may simply have higher nonconspicuous demand for high-end goods than households in other MSAs so they are more likely

\footnotetext{
${ }^{6}$ We use the annual data of the number of new single-family houses sold by sales price from Census. These data are available only at the 4 census region level and summarized for 7 price ranges: below $\$ 125,000, \$ 125,000-199,999$, $\$ 200,000-299,999, \$ 300,000-399,999, \$ 400,000-499,999, \$ 500,000-749,999$, above $\$ 750,000$. While relying on region-level data, we attempt to account for heterogeneous price distribution in housing markets across MSAs. For each MSA, we use the number of housing units from the region which a MSA belongs to and from the price range that includes the top 10\% and median house prices of this MSA. For example, when the median house price of a MSA in the South region is $\$ 320,000$, we used the number of housing units sold in the South region for the price range of $\$ 300,000-399,999$ as the median housing units sold.

${ }^{7}$ With this measure of the availability of high-end rental units relative to high-end owner occupied units, we account for differences in the standard of high-end housing between different MSAs and different years. If the standard for high-end housing is high, the share of high-end rental units gets adjusted downward and if the standard for high-end rental units is low, it gets adjusted upward.
} 
to aspire to these goods and pay higher housing premiums. To account for this, we add the income distribution (ratio of the top 10\% household income to the median income). Most demographic and housing market data are from American Community Survey (ACS) and the data on dissimilarity indices are from the U.S. Census Bureau. Table 1 summarizes these variables used for regression analyses.

After matching the data from Google Insights for Search with the Dataquick data, the final sample consists of 101 MSAs for 32 quarters (8 years) from 2004 to 2011 (11 MSAs from Northeast region, 24 MSAs from Midwest region, 37 MSAs from South region, and 29 MSAs from West region). During the study period between 2004 and 2011, housing markets in most MSAs experienced the cycle of boom and bust and it is plausible to expect that the disturbances (housing premium shocks) are serially correlated. ${ }^{8}$ Therefore, we use a dynamic panel model that includes the lagged dependent variable as one of independent variables although a coefficient on the lagged dependent variable is not of direct interest, following Blundell and Bond (2000). Since OLS with a lagged dependent variable and serially correlated error could lead to inconsistent parameter estimates, we utilize the GMM estimator for dynamic panel models. In GMM based estimation proposed by Arellano and Bond (1991), first differenced transformed series are used to adjust the unobserved individual specific heterogeneity in the series. It also assumes that only available instruments are internal based on lags of the instrumented variables. However, Blundell and Bond (1998) report that the difference-GMM has poor finite sample properties in terms of bias and precision when the series are persistent and the instruments are weak predictors of the endogenous changes. Also, the difference-GMM eliminates the cross-

\footnotetext{
${ }^{8}$ In fact, Wooldridge test rejected no first-order autocorrelation hypothesis when we use the static panel regression model $(F=25.785, p<0.00)$.
} 
MSA relationship and focuses only on time differences. Arellano and Bover (1995) and Blundell and Bond (1998) propose a system-based approach to overcome these limitations in the dynamic panel data.

Therefore, we use the system GMM with first differences with one-step estimation. The dependent variable (housing premiums) lagged by one quarter was included as one of independent control variables. Housing premiums and the main independent variable (conspicuous demand) are treated as endogenous variables and their first and second lagged variables are used as instruments. Other control variables are treated as exogenous variables. Time dummies are also included to validate the assumption that no correlation across individuals in the idiosyncratic disturbances exists as Roodman (2006) suggested.

Our study period allows our examination both in the boom and bust periods. To define the boom period and the bust period, we followed the method used by Sinai (2012). Briefly, we obtained the Federal Housing Finance Agency (FHFA)'s quarterly house price index from data on repeat sales of homes (i.e. constant quality house price index) for MSAs. We converted the price indexes from nominal to real terms by deflating using the CPI (all urban consumers). For each MSA, we identified the peak by finding all the local maxima, quarters where the real house price is above those of adjacent quarters from 2004 to 2011. Then, we chose the local maximum with the highest real house price. In addition, to examine spatial variation of the relationship between conspicuous demand and housing premiums, we divided 101 MSAs into top 30\%, middle 40\%, and bottom $30 \%$ groups based on the price deviation of high-end houses from the median price 
(housing premiums) averaged over the study period. Thus, we ran regressions for the full sample and for sub premium groups both before the peak quarters (inclusive) and after the peak quarters.

\section{Results}

\section{Descriptive Statistics}

Figure 1 compares housing markets and conspicuous demand in New York and Seattle Metropolitan Statistical Areas (MSAs). This comparison is interesting because both MSAs have relatively strong and tight housing markets and income level is very similar. ${ }^{9}$ Figure 1 suggests that while the level of median house prices is similar in two MSAs, homebuyers tend to pay a lot higher housing premium in New York (average \$444,955) than in Seattle (average \$332,433). It also shows that conspicuous demand, calculated by the search volume of luxury brands relative to the search volume of the product, is significantly higher across all categories in New York than in Seattle, suggesting the potential relationship between conspicuous demand and housing premiums. In both MSAs, when consumers became less interested in searching for luxury watches and perfume starting in 2007 Q3, the house price has decreased at all the price levels. Although we also find that a drop in the house premium is more distinct in New York right after this peak quarter, it quickly comes back to the origin level. For example, homebuyers in New York still pay about $\$ 442,541$ in 2010 compared to what homebuyers pay for the premium $(\$ 293,782)$ in Seattle. This potentially indicates that conspicuous demand could contribute to maintaining the level of housing premiums even during the bust period.

\footnotetext{
${ }^{9}$ Of course, they present a difference in other socioeconomic characteristics. Later for our formal statistical analyses, we will control for these characteristics.
} 
Then, Figure 2 compares New York with Las Vegas, another MSA with a high level of conspicuous demand. While the degree of consumers' desire for luxury goods is similar at the peak quarter in two MSAs, this desire, especially for watches and perfume, changes much more dramatically in Las Vegas than in New York. Based on the Case-Shiller (CS) tiered price Index, we find that Las Vegas shows much higher volatility in house prices for the middle-tier and hightier homes. If a dramatic change in conspicuous demand had been translated into housing consumption behavior in Las Vegas, this may have affected a significant price change in the MSA's housing market. ${ }^{10}$ The premium paid for homes in the highest decile has also dropped substantially (more than 23\%) in Las Vegas after the peak quarter (not shown). On the other hand, New York shows that the high-tier CS index was much more stable (Figure 2) and the premium was maintained at a similar level (not shown) even during the bust period. This result suggests that MSAs with the volatile conspicuous demand are likely to be more vulnerable to a substantial change in the housing premium.

We further identify 5 MSAs with the highest conspicuous demand and 5 MSAs with the lowest conspicuous demand among 17 major MSAs where the CS tiered index is available. ${ }^{11}$ Since this rank is based on the average conspicuous demand over time, people residing in the top 5 MSAs are likely to show the relatively stable, higher desire for the non-housing luxury consumption than other MSAs. ${ }^{12}$ Table 2 shows how housing market dynamics differ between these MSAs

\footnotetext{
${ }^{10} \mathrm{We}$ acknowledge that there may be many out-of-MSA housing participants in some MSAs, especially the markets like Las Vegas, and this may not be captured by our measures of conspicuous demand. In the later section, we address this issue and separate external demand from internal demand.

${ }^{11}$ Although the CS tiered index could be a more precise indicator of the change in difference tiered prices than the data calculated based on Dataquick, it is available only for 17 MSAs. Therefore, we still use Dataquick data for our main statistical analyses.

${ }^{12}$ For example, Las Vegas shows the high conspicuous demand at the peak year but its conspicuous demand is very volatile. While it does not belong to top 5 MSAs, therefore, New York does.
} 
and MSAs with the lower level of consumers' desire for non-housing luxury goods during the boom and bust periods.

During the boom period, MSAs with the higher conspicuous demand have experienced a much higher increase in both aggregate and high-tier HPIs compared with other MSAs. In particular, the premium paid for homes in the highest decile in these areas is as twice high as housing premiums in other MSAs. During the bust period, MSAs with the higher conspicuous demand have experienced a lower drop in HPIs, especially in high-tier HPIs, than other MSAs. In addition, the premiums for homes in the highest decile and quartile are well maintained in these MSAs. These results basically tell us the similar story as the New York MSA that the stable, high conspicuous demand is significantly associated with an increase in the housing premium during the boom period while being also related with higher housing premiums even during the bust period. To further validate this association, we will control for variation in economic and demographic characteristics across MSAs and quarters for our statistical analyses.

Table 3 summarizes descriptive statistics of all variables used in the regression analyses for the study period between 2004 and 2011. In addition to the statistics for the full sample of 3232 observations (101 MSAs), we present those for two sub-samples: a high-premium sample that includes the top 30\% of MSAs (30 MSAs) and a low-premium sample that includes the bottom $30 \%$ of MSAs (31 MSAs) — both based on the average price deviation of high-end houses from the median price (housing premiums) over the study period. The list of MSAs in these subgroups is provided in Appendix B. For each variable, the between (across MSAs) standard 
deviation and the within (over time within MSA) standard deviation are shown as well as the overall standard deviation. Detailed descriptions of these variables are provided in Table 1.

On average, there is a $\$ 182,003$ difference between the top $10 \%$ of house price and the median house price in the full sample. In high-premium MSAs, homebuyers pay a premium of $\$ 288,595$; meanwhile, homebuyers pay a premium of $\$ 112,069$ in low-premium MSAs (less than forty percent of the premium for the high-premium group). Most importantly, all the conspicuous demand measures (i.e., ratios of brand search to product search in four different categories) show the same pattern, having higher-than-average ratios for the high-premium group and lower-thanaverage ratios for the low-premium group. For example, conspicuous demand for the fashion category in the high-premium group $(0.169)$ is more than double conspicuous demand in the low-premium group (0.064), thereby strongly suggesting the existence of a clear association between these two constructs - namely, in MSAs with high (low) conspicuous demand, people pay high (low) premiums for high-end houses, which is consistent with our hypothesis.

Control variables also show notable differences between sub-groups in Table 3. Compared to low-premium MSAs, high-premium MSAs tend to have a larger population, higher median age, and larger household size. Regarding housing market conditions, households tend to pay higher housing premiums in MSAs with more new housing (both stock and construction) but with fewer high-end housing options (i.e. fewer new house sales in the high-end price range and fewer highend rental units). Median household income is higher and income gap between top decile and median is larger in high-premium MSAs while these MSAs are slightly more segregated. Although variation in most variables comes from across MSAs (between) rather than over time 
(within), conspicuous demand shown in the perfume category, building permits, availability of high-end rental units relative to high-end owner-occupied units, and top-decile to median income ratio show slightly higher variation over time than across MSAs.

\section{Estimation Results}

Table 4 shows results of the dynamic panel system GMM regressions using the full sample for the entire study period of 2004-2011. In this table, a dependent variable is the log of housing premiums and the main independent variable is the ratio of the brand search to the product search in the automobile category (conspicuous demand). We chose the automobile category as a representative for the main analysis because it covers most expensive and most visible luxury products whose consumptions are expected to be motivated greatly by conspicuous demand. ${ }^{13}$ While the first model contains only the main independent variable (conspicuous demand) and the lagged housing premium (serial correlation), the second model includes controls for basic demographics and the third model adds housing market controls. The fourth model is the most comprehensive one that includes the dissimilarity index, median household income (ability to pay for high-end goods), and income distribution (demand for high-end goods) along with other control variables.

Overall, after controlling for serial correlation, we find that conspicuous demand has a significant, positive relationship with housing premiums $(B=0.364,0.289,0.299$, and 0.336 for

\footnotetext{
13 The results for other categories are provided in Appendix $\mathrm{C}$ and discussed as one of the robustness checks in the following section.
} 
the four models, respectively; all of them are significant at the $1 \%$ level). ${ }^{14}$ MSAs and periods with high (low) conspicuous demand extracted via a Google search exhibit high (low) housing premiums. Our conspicuous demand measure proxies the degree to which consumers desire conspicuous goods and services to flaunt their wealth and achieve greater social status, even at higher prices than their intrinsic values. When/where people show strong conspicuous demand, they may also consume certain types of houses according to the same motivation. Thus, the strong, positive relationship of conspicuous demand measure with housing premiums as shown in Table 4 suggests that high-end houses - which are often conspicuous in terms of location, quality of neighbor, size, and design — are purchased for the enjoyment of signaling their wealth and status, which at least partly drives the large deviation of high-end house prices from the median house price. Even though it is difficult to extract conspicuous demand from wealth effects and demand for more general high-end goods, the observed relationship between our measure of conspicuous demand and housing premiums remains significant and positive even after controlling for wealth conditions and general demand for high-end goods (Model 4 of Table 4). ${ }^{15}$

The fourth model in Table 4 also shows that conspicuous demand still plays a strong significant role in explaining the housing premium even after controlling for fundamental demographics, housing market conditions, median household income, income distributions, and dissimilarity

\footnotetext{
${ }^{14}$ Note that the estimate of the lagged dependent variable in our system GMM regression (.774) lies between the upper bound of the OLS model (.934) and the lower bound of the fixed effect model (.583). Following Nerlove (1971), this suggests that coefficients of our GMM system estimation are actually consistent.

${ }^{15}$ Since the number of units (MSAs) is not very large, we used first and second lagged variables of instrumented variables as instruments, mainly to reduce the number of instruments. As a robustness check, we tried another method of reducing the instrument count, following Mehrhoff (2009). We used all the lags of instrumented variables expect first lags. Then, we applied principal components analysis to the GMM-style instruments and kept only the largest components (60 components in total). This alternative model has 103 instruments and shows essentially the same main results without rejecting (properly) Hansen test of overidentification $(p=0.121)$.
} 
indices (Asian-White and Black-White). Results for several control variables are noteworthy. First, housing premiums tend to be higher in MSAs/periods that have a larger population, higher age, and larger household size. Second, we find a significant, negative relationship between housing premiums and new construction (building permits). New construction is a proxy for supply elasticity and the translation of conspicuous demand into housing premiums would not be significant if markets react quickly to such demand and build more high-end houses. Third, housing premiums tend to be higher in MSAs with fewer high-end housing options (fewer new house sales in the high-end price range relative to median price range and lower availability of high-end rental units relative to high-end owner-occupied units). Finally, homebuyers are likely to pay higher housing premiums in MSAs where median household income is higher and income gap between top decile and median is larger while they tend to pay lower premium in MSAs with higher Black-White segregation.

Although we find the significant relationship between conspicuous demand and housing premiums using the full sample over the entire study period, it is plausible to expect that housing consumption behaviors motivated by conspicuous demand are more evident among MSAs with high premiums than among MSAs with low premiums. In addition, the relationship between housing premiums and conspicuous demand during a housing boom may be different from the relationship during a housing bust. Therefore, we conducted analyses for the top 30\% of the housing premium group both before the peak quarter (boom period) and after the peak quarter (bust period) as well as for the bottom $30 \%$ of the housing premium group in both boom and bust periods. We identified the peak quarter for each MSA using the Sinai's (2012) method, as explained in the previous section. 
Table 5 summarizes the results of these sub-sample regressions. Most importantly, the results clearly indicate that conspicuous demand has a much more significant, positive relationship with housing premiums among MSAs within the top $30 \%$ of the housing premiums than among MSAs within the bottom $30 \%$ housing premium group. In the bottom $30 \%$ housing premium group, no significant relationship between conspicuous demand and housing premiums emerges during the bust period. In the top $30 \%$ group, conspicuous demand exhibits a significant, positive relationship with housing premiums during both boom $(B=0.524, p<0.00)$ and bust periods $(B$ $=0.398, p=0.01)$. As conspicuous demand in the top $30 \%$ group tends to stay at a high level even after the peak quarter, ${ }^{16}$ conspicuous demand may be related with higher housing premiums during the bust period in this group. Appendix D illustrates such a situation using San FranciscoOakland-Fremont (CA) as an example.

Results for several control variables in regressions are worth mentioning. Table 5 shows that the dissimilarity index for Asian-White becomes to have a significant, positive relationship with housing premiums in the top $30 \%$ premium group while we observed no such relationship for the bottom 30\% premium group (Table 5) and the full sample (Table 4). This suggests segregation premiums paid by both Whites and Asian. On the one hand, affluent Whites may be willing to pay to avoid Asian-dominated neighborhoods. On the other hand, middle- to high-income Asians may be willing to pay to sort themselves into the ethnic enclaves or neighborhoods with better educational quality. For example, the top 4 MSAs in the top $30 \%$ housing premium group are

\footnotetext{
${ }^{16}$ The temporal dynamics of conspicuous demand in these MSAs are consistent with those of LVMH business performance. The LVMH profit in the fashion and leather goods segment has increased since $2008(1,927$ EUR million) for several years during the recession (1,986 EUR million in 2009; 2,555 EUR million in 2010; 3,075 EUR million in 2011) according to LVMH's annual reports.
} 
located in California known to have many Asian enclaves with relatively higher educational quality (Appendix B).

Median household income and the ratio of top $10 \%$ to median household income have no significant relationship with housing premiums during the boom period (before peak year) with both sub-samples while we observed that these wealth and wealth distribution variables are significantly associated with housing premiums for the full sample (Table 4). This result implies that households may exhibit unique housing consumption behavior during the boom period, which cannot be explained by their fundamental ability to pay for high-end goods. At least part of this unique consumption behavior, which contributes to raising housing premiums, seems to be explained by conspicuous demand.

\section{Robustness Checks}

To begin with, while our previous results suggest the strong, significant relationship between our Google search measure of conspicuous demand and housing premiums, it is arguable that tourists and visitors may have significantly contributed Google search queries in some MSAs. Similarly, housing premiums in certain MSAs may have been affected by demand for high-end houses from buyers and investors who reside outside these MSAs. ${ }^{17}$ To examine and control for such external demand, we collected the data on the number of overseas visitors to each MSA from the International Trade Administration (average of 2004 and 2005) and used it as a proxy for external demand in luxury goods markets (overseas visitors). We also collected the data on the

\footnotetext{
${ }^{17}$ As the growing literature suggests, spatial concentration of the housing bubble and unusual house price variation in some MSAs, especially in sand states, may have been influenced by purchases by investors, and specifically by investors residing outside these MSAs (Wheaton and Nechayev 2006).
} 
annual number of vacation homes in each MSA and calculated the ratio of the number of vacation homes to the number of single-family houses as a proxy for external demand in housing markets (vacation home ratio). Table 6 shows results of dynamic panel system GMM regressions that include external demand control variables along with all the other control variables. ${ }^{18}$ Table 6 suggests that the interaction term has a significant negative relationship with housing premiums in both models. In MSAs where much demand for high-end houses is from nonresident buyers (i.e. higher vacation home ratios), the relationship between conspicuous demand and housing premiums becomes weaker, because conspicuous demand of buyers residing outside MSAs cannot be captured by Google search queries within these MSAs. Similarly, in MSAs where tourists and visitors significantly contribute to the Google search for luxury brands (i.e. higher overseas visitors), the relationship between conspicuous demand and housing premiums is weakened, because demand for high-end houses of tourists are not likely to be reflected in housing premiums within these MSAs. Still, results in Table 6 confirm that the observed relationship between our conspicuous demand proxy and housing premiums remain significant and positive even after controlling for external demand. ${ }^{19}$

Second, one might be concerned about the accuracy of our measures of conspicuous demand. Hence, we try several alternative measures as robustness checks. ${ }^{20}$ First, we run our regressions using Google search data for other categories than automobile as a main independent variable.

\footnotetext{
${ }^{18}$ Before running regressions, we first found a strong, positive link between external demand in luxury goods markets and external demand in housing markets: the average number of overseas visitors is 498,683 among the top $30 \%$ vacation home ratio group (where the share of vacation homes is relative higher) while the average number of overseas visitors is only 134,274 among the bottom $30 \%$ vacation home ratio group (where the share of vacation homes is relative lower).

${ }^{19}$ Even among the top 30\% vacation home ratio group, conspicuous demand has a significant, positive relationship with housing premiums $(B=0.166, p=0.07)$.

${ }^{20}$ Unreported robustness check results are available from the authors upon request.
} 
As presented in Appendix C, results confirm that the choice of the product category does not change main interpretations and conclusions. ${ }^{21}$ In addition, for the sub-samples based on the housing premium groups (top 30\% and bottom 30\%) during both the boom and bust periods, we run regressions using conspicuous demand measure for the fashion-leather category. Results are almost identical to Table 5 obtained using the measure for the automobile category (Table 5). Second, our measures of conspicuous demand may also capture non-conspicuous, genuine demand for luxury products. In particular, the cosmetics-perfume category are less visible and less likely to be consumed to signal wealth and status. In an attempt to distinguish conspicuous demand from non-conspicuous, genuine demand for luxury goods, we add the ratio of cosmeticsperfume brand search to cosmetics-perfume product search as an additional control variable. Using the same dynamic panel system GMM regression, we still find a significant, positive relationship between conspicuous demand in the automobile category and housing premium $(B=$ 0.531, $p<0.00)$, while the cosmetics-perfume control variable is insignificant $(B=0.002, p=$ 0.820). Third, among all luxury brands we used in the main analysis, we create the list of top brands for the fashion-leather and watch-jewelry category (see Appendix A) and run our regressions using Google search data for these top brands. Results still suggest a significant, positive relationship between these measures of conspicuous demand and housing premiums (not shown). ${ }^{22}$ Finally, we collected the data on the number of Louis Vuitton stores in each MSA as of 2014 and use it as a main independent variable instead of Google search data. ${ }^{23}$ The result of the dynamic panel system GMM regression suggests that controlling for all variables used for the

\footnotetext{
${ }^{21}$ The only exception is the cosmetics-perfume category which is less visible compared to other product categories.

${ }^{22}$ A coefficient with top luxury brands in the fashion category is $B=1.229$ ( $p<0.00$ ). A coefficient with top luxury brands in the watch category is $\mathrm{B}=1.288(\mathrm{p}<0.00)$.

23 The average number of Louis Vuitton stores per MSA is 2.22 with the standard deviation of 2.92, the minimum of 0 , and the maximum of 17 (New York).
} 
main analysis, conspicuous demand measured by the number of Louis Vuitton stores also has a significant, positive relationship with housing premiums $(B=0.003, p<0.00)$.

A final concern is related to our measure of housing premiums. In our previous analyses, we used an absolute dollar difference between the top decile and median house prices as a dependent variable. As a robustness check, we redefine a ratio of the top docile house price to the median house price as housing premiums and reran our regressions. Results are quite robust, suggesting that conspicuous demand has a significant, positive relationship with this new measure of housing premiums $(B=0.118, \mathrm{p}=0.076)$ controlling for same variables used in the main analysis (Table 4, Column 4).

\section{Concluding Remarks}

Given the plausible relationship between the consumers' desire for non-housing luxury goods and housing consumption behavior, this study is the first to examine the actual association between conspicuous demand and housing price dynamics. Results from dynamic panel regressions suggest that controlling for the MSA's demographic and economic characteristics, housing premiums paid for high-end homes are much higher in MSAs with higher conspicuous demand than in other MSAs. There is spatial and temporal variation in the relationship between conspicuous demand and housing premiums. During the boom period we observe that conspicuous demand has a stronger relationship with an increase in housing premiums in MSAs with a steady, higher premium for high-end homes than in MSAs with a more volatile, lower premium. Also evident is that in MSAs with a steady, higher premium, conspicuous demand has a significant, positive relationship with housing premiums even during the bust period. 
These results suggest that high-end houses located in the highly conspicuous MSAs may have been purchased for the enjoyment of signaling wealth and status rather than for the intrinsic values of these houses. Hence, this housing consumption behavior could partly explain higher housing premiums paid in certain MSAs. This study also provides important insights into the reasons behind temporal changes in the housing premium. If we observe non-housing luxury consumption becomes substantially higher or lower in certain MSAs compared to previous time periods, this could be a potential indicator of the significant increase or decrease in the housing premium in these MSAs. Further, we are likely to find higher volatility in the housing premium in the areas where consumers' desire for luxury consumption changes dramatically over time. The results will be also of great importance for developers in the process of home development and for real estate agents in price determination and negotiation processes. If we consistently observe that conspicuous demand is translated into housing consumption more substantially in certain areas, we would expect higher demand for high-end homes in these areas even during the bust period.

\section{Acknowledgements}




\section{References}

Aït-Sahalia, Y., Parker, J. A., and Yogo, M. (2004). Luxury Goods and the Equity Premium. Journal of Finance, 59(6), 2959-3004.

Arellano, M. and Bond, S. (1991). Some Tests of Specification for Panel Data: Monte Carlo Evidence and an Application to Employment Equations. Review of Economic Studies, 58(2), 277-297.

Arellano, M. and Bover, O. (1995). Another Look at the Instrumental Variable Estimation of Error-Component Models. Journal of Econometrics, 68(1), 29-51.

Bagwell, L. S. and Bernheim, B. D. (1996). Veblen Effects in a Theory of Conspicuous Consumption. American Economic Review, 86(3), 349-373.

Blundell, R. and Bond, S. (1998). Initial Conditions and Moment Restrictions in Dynamic Panel Data Models. Journal of Econometrics, 87(1), 115-143.

Blundell, R. and Bond, S. (2000). GMM Estimation with Persistent Panel Data: An Application to Production Functions. Econometric Reviews, 19(3), 321-340.

Case, K. E. and Shiller, R. J. (2004). Is There a Bubble in the Housing Market?: Cowles Foundation for Research in Economics Yale University.

Chao, A. and Schor, J. B. (1998). Empirical Tests of Status Consumption: Evidence from Women's Cosmetics. Journal of Economic Psychology, 19(1), 107-131.

Chevalier, M. and Mazzalovo, G. (2008). Luxury Brand Management: A World of Privilege. Wiley and Sons.

Choi, H. and Varian, H. (2012). Predicting the Present with Google Trends. The Economic Record, 88(s1), 2-9.

Chosun.com. (2012). Ever-Popular Chanel to Raise Handbag Prices Again. The Chosunilbo. Retrieved January 20, 2012.

Corneo, G. and Jeanne, O. (1997). Conspicuous Consumption, Snobbism and Conformism. Journal of Public Economics, 66(1), 55-71.

Crowder, K. D. (2000). The Racial Context of White Mobility: An Individual-Level Assessment of the White Flight Hypothesis. Social Science Research, 29(2), 223-257.

Cutler, D. M., Glaeser, E. L., and Vigdor, J. L. (1999). The Rise and Decline of the American Ghetto. Journal of Political Economy, 107(3), 455-506. 
Da, Z., Engelberg, J., and Gao, P. (2011). In Search of Attention. Journal of Finance, 66(5), 1461-1499.

Ferreira, F. and Gyourko, J. (2011). Anatomy of the Beginning of the Housing Boom: U.S. Neighborhoods and Metropolitan Areas, 1993-2009.Unpublished manuscript, The Wharton School, University of Pennsylvania \& NBER.

Hiraki, T., Ito, A., Spieth, D. A., and Takezawa, N. (2009). How Did Japanese Investments Influence International Art Prices? Journal of Financial and Quantitative Analysis, 44(6), 1489.

Luxury Institute (2010). Leading Edge Insights into the World of the Wealthy. Luxury Institute research report.

Leguizamon, S. (2010). The Influence of Reference Group House Size on House Price. Real Estate Economics, 38(3), 507-527.

Mandel, B. R. (2009). Art as an Investment and Conspicuous Consumption Good. American Economic Review, 99(4), 1656-1663.

Mehrhoff, J. (2009). A Solution to the Problem of Too Many Instruments in Dynamic Panel Data GMM. Deutsche Bundesbank Discussion Paper Number 31.

Merrill Lynch (2007). Launching the ML Lifestyle Index. Merrill Lynch research report.

Nerlove, Marc (1971). Further Evidence on the Estimation of Dynamic Economic Relations from a Time Series of Cross Sections. Econometrica, 39(2), 359-382.

Roodman, D. (2006). How to do xtabond2: An Introduction to "Difference" and "System" GMM in Stata. Center for Global Development Working Paper Number 103.

Shukla, P. (2008). Conspicuous Consumption Among Middle Age Consumers: Psychological and Brand Antecedents. Journal of Product \& Brand Management, 17(1), 25-36.

Sinai, T. (2012). House Price Moments in Boom-Bust Cycles. NBER Working Papers 18059.

Stiglitz, J. E. (1990). Symposium on Bubbles. Journal of Economic Perspectives, 4(2), 13-18.

Strach, P. and Everett A. M. (2006). Brand Corrosion: Mass-Marketing's Threat to Luxury Automobile Brands after Merger and Acquisition. Journal of Product \& Brand Management, 15(2), $106-120$.

Turnbull, G. K., Dombrow, J., and Sirmans, C. F. (2006). Big House, Little House: Relative Size and Value. Real Estate Economics, 34(3), 439-456.

Uche, O. (2007). Luxury Fashion Branding: Trends, Tactics, Techniques. Palgrave Macmillan. 
Veblen, T. (1899). The Theory of the Leisure Class. New York, London: The Macmillan Company.

Wheaton, W, and G. Nechayev. (2006). Past housing cycles and the current housing boom: What's different this time. Manuscript, MIT.

Yamawaki, H. (2002). Price Reactions to New Competition: A Study of US Luxury Car Market, 1986-1997. International Journal of Industrial Organization, 20(1), 19-39.

Zahirovic-Herbert, V. and Chatterjee, S. (2011). What is the Value of a Name? Conspicuous Consumption and House Prices. Journal of Real Estate Research, 33(1), 105-125. 
Figure 1 Housing Markets and Conspicuous Demand in New York and Seattle MSAs
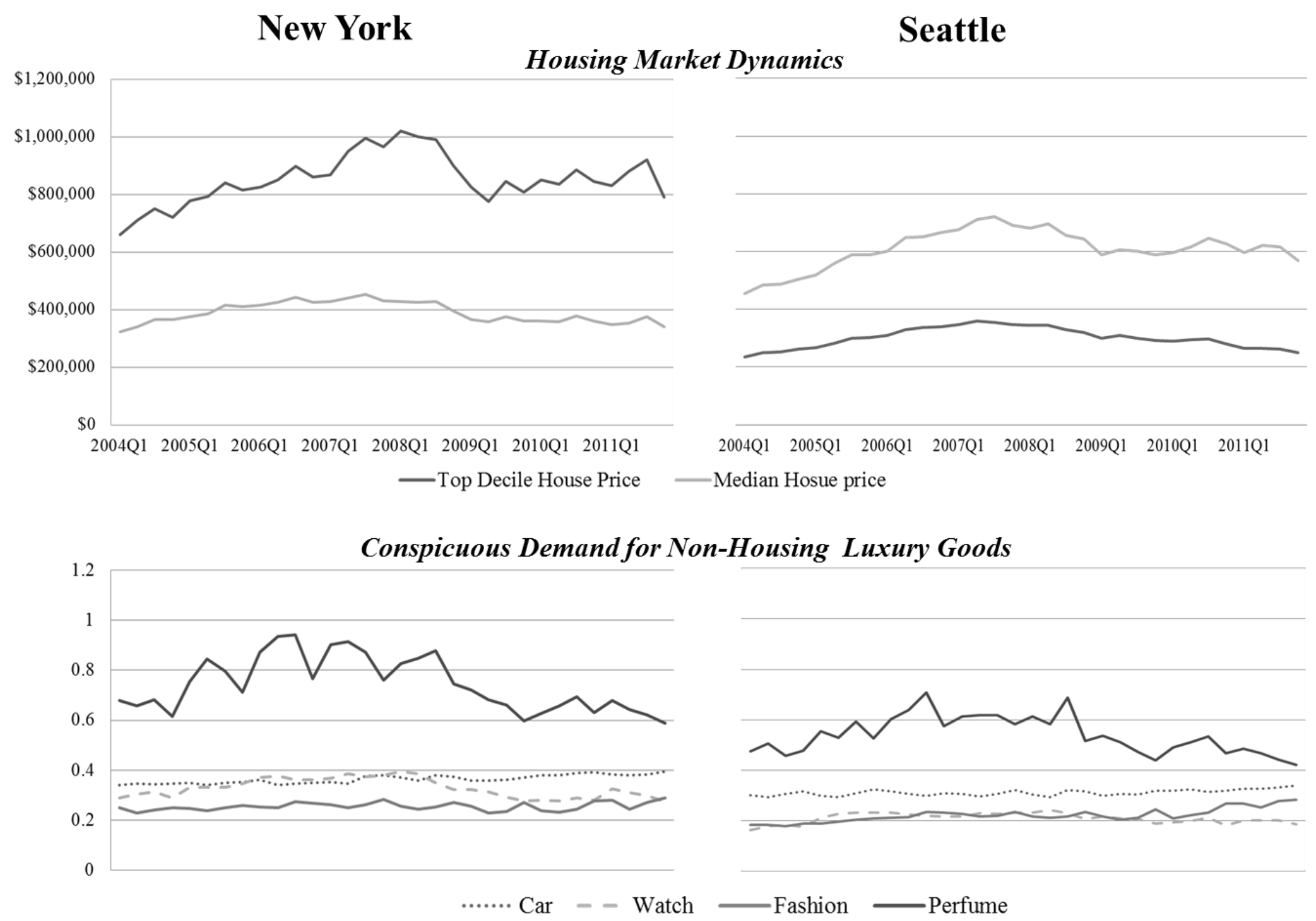
Figure 2 Housing Markets and Conspicuous Demand in New York and Las Vegas MSAs

\section{New York}

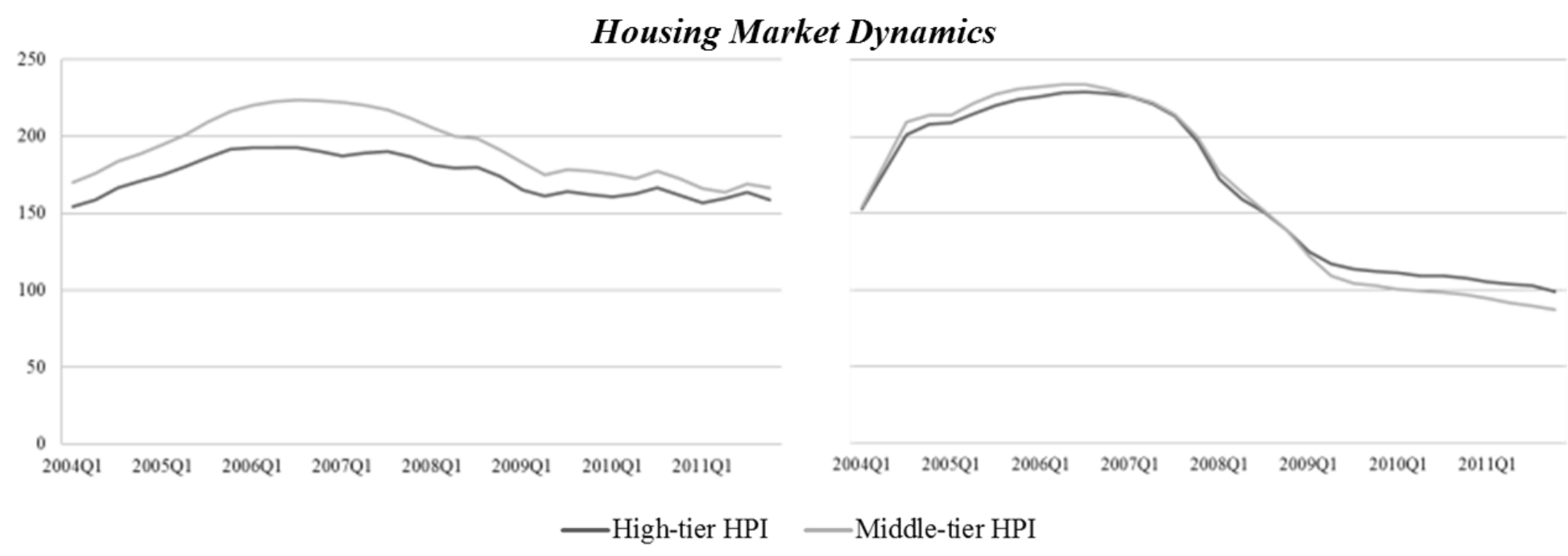

\section{Las Vegas}

Conspicuous Demand for Non-Housing Luxury Goods

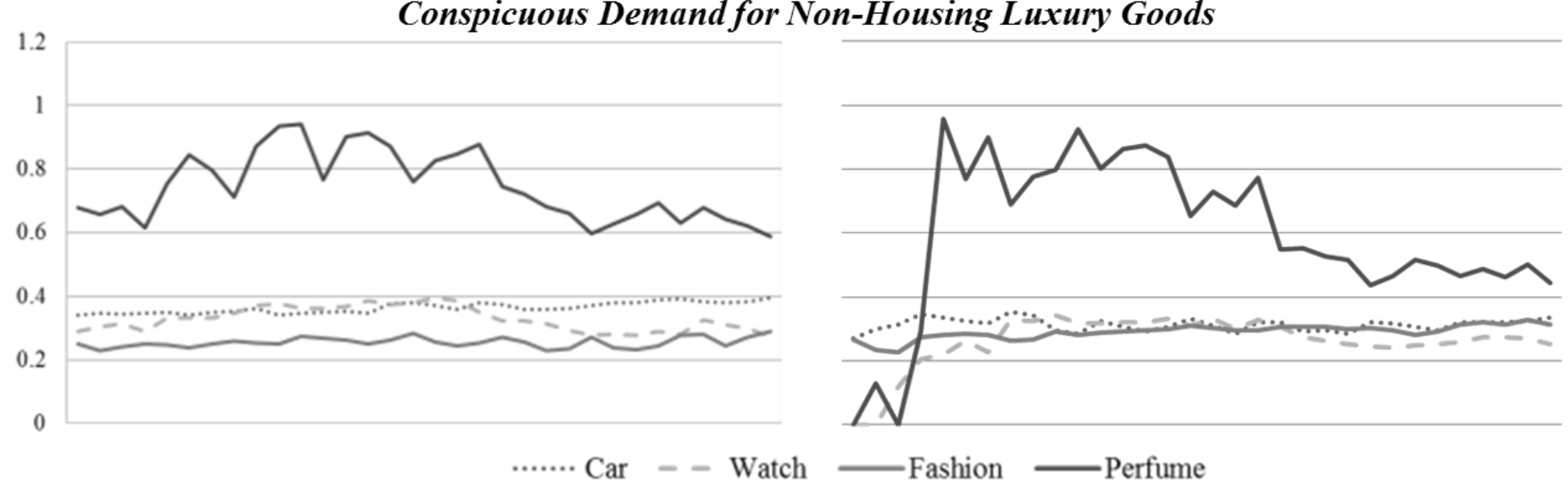




\section{Table 1 Dependent Variable and Independent Variables}

\section{Dependent variable}

Top $10 \%$ house price minus median house price (log)

Luxury Conspicuous Demand

Lux search(car)

Lux search(fashion)

Lux search(watch)

Lux search(perfume)

\section{Demographics}

Population $(\log )$

Median age

Median household size

Housing market

$\%$ year built after 2000

Building permits

Change of building permits

Ratio of top $10 \%$ housing units sold to median housing units sold

Ratio of high-end rental units to high-end owner-occupied units

Dissimilarity index

D-index (Asian)

D-index (Black)

Wealth

Median household

income $(\log )$

Demand for high-end goods

Ratio of top $10 \%$ income to median income
Log of top $10 \%$ house price minus median house price within each MSA in each quarter in real term

Ratio of automobile brand search to automobile product search for each MSA in each quarter

Ratio of fashion-leather brand search to fashion-leather product search for each MSA in each quarter

Ratio of watch-jewelry brand search to watch-jewelry product search for each MSA in each quarter

Ratio of cosmetics-perfume brand search to cosmeticsperfume product search for each MSA in each quarter

Log of population for each MSA in each year

Median age for each MSA in each year

Median household size for each MSA in each year

Proportion of houses build after 2000 for each MSA in each year

Log of the number of building permits (single-family) for each MSA in each year

Annual percentage change of the number of building permits (single-family) for each MSA in each year Ratio of the number of new single-family houses sold (annual statistics for four census regions) in the top 10\% price range defined for each MSA to those sold in the median price range also defined for each MSA

Ratio of the number of rental units with contract rent above $\$ 1,500$ to the number of owner-occupied units with price above $\$ 1,000,000$ for each MSA in each year

Dissimilarity index (Asian-White) for MSA as of 2000

Dissimilarity index (Black-White) for MSA as of 2000

Log of median household income for each MSA in each year

Ratio of top $10 \%$ household income to median household income for each MSA in each year 
Table 2 Housing Markets of MSAs with the Different Level of Conspicuous Demand

\begin{tabular}{lrrr}
\hline & $\begin{array}{l}\text { 5 MSAs with } \\
\text { the highest } \\
\text { conspicuous } \\
\text { demand }^{1}\end{array}$ & $\begin{array}{l}\text { 5 MSAs with } \\
\text { the lowest } \\
\text { conspicuous } \\
\text { demand }^{2}\end{array}$ & $\begin{array}{l}\text { All other } \\
\text { MSAs }\end{array}$ \\
\hline $\begin{array}{l}\text { During the boom period } \\
\text { Annual change in aggregate HPIs }\end{array}$ & $8.84 \%$ & $5.89 \%$ & $6.29 \%$ \\
Annual change in high-tier HPIs & $8.54 \%$ & $5.21 \%$ & $5.73 \%$ \\
Premium for homes in the highest decile & $\$ 452,227$ & $\$ 217,783$ & $\$ 236,677$ \\
Premium for homes in the highest quartile & $\$ 188,168$ & $\$ 92,242$ & $\$ 103,761$ \\
During the bust period & & & \\
Annual change in aggregate HPIs & $-8.54 \%$ & $-8.79 \%$ & $-9.43 \%$ \\
Annual change in high-tier HPIs & $-6.67 \%$ & $-7.68 \%$ & $-8.05 \%$ \\
Premium for homes in the highest decile & $\$ 433,733$ & $\$ 214,470$ & $\$ 266,667$ \\
Premium for homes in the highest quartile & $\$ 181,436$ & $\$ 83,675$ & $\$ 105,511$ \\
\hline
\end{tabular}

Note 1. San Francisco, Los Angeles, New York, Washington DC, and Miami

2. Tampa, Seattle, Portland, Minneapolis, and Cleveland

3. Boom periods are when MSA HPI increases and bust periods are when MSA HPI decreases. They are determined based on the CS aggregate index.

4. HPIs are from the CS tiered index and premiums are from Dataquick. 
$\underline{\text { Table } 3 \text { Descriptive Statistics for a Dependent Variable and Independent Variables }}$

\begin{tabular}{|c|c|c|c|c|c|c|c|c|c|c|c|c|}
\hline \multirow{4}{*}{ Variable } & \multirow{2}{*}{\multicolumn{4}{|c|}{ Full Sample }} & \multicolumn{8}{|c|}{ Housing premium $^{1}$} \\
\hline & & & & & \multicolumn{4}{|c|}{ High-premium } & \multicolumn{4}{|c|}{ Low-premium } \\
\hline & \multirow{2}{*}{ Mean- } & \multicolumn{3}{|c|}{ Standard Deviation } & \multicolumn{4}{|c|}{ Standard Deviation } & \multirow{2}{*}{ Mean- } & \multicolumn{3}{|c|}{ Standard Deviation } \\
\hline & & overall & between $^{2}$ & within $^{3}$ & Mean- & overall & between & within & & overall & between & within \\
\hline $\begin{array}{l}\text { Top } 10 \% \text { house price minus } \\
\text { median house price }\end{array}$ & 182,003 & 105,751 & 100,409 & 34,613 & 288,595 & 139,125 & 128,155 & 58,847 & 112,069 & 18,401 & 13,637 & 12,587 \\
\hline Lux search(automobile) & 0.255 & 0.080 & 0.071 & 0.037 & 0.313 & 0.062 & 0.056 & 0.029 & 0.193 & 0.085 & 0.069 & 0.052 \\
\hline Lux search(fashion) & 0.117 & 0.070 & 0.063 & 0.033 & 0.169 & 0.064 & 0.059 & 0.028 & 0.064 & 0.059 & 0.049 & 0.034 \\
\hline Lux search(watch) & 0.142 & 0.099 & 0.088 & 0.047 & 0.209 & 0.089 & 0.079 & 0.045 & 0.072 & 0.081 & 0.070 & 0.043 \\
\hline Lux search(perfume) & 0.467 & 0.310 & 0.217 & 0.241 & 0.590 & 0.338 & 0.123 & 0.318 & 0.294 & 0.297 & 0.238 & 0.191 \\
\hline Population $^{5}$ & $1,790,471$ & $2,621,962$ & $2,631,673$ & 95,162 & $3,549,962$ & $3,959,210$ & 402,304 & 116,804 & 605,926 & 499,942 & 506,075 & 42,913 \\
\hline Median age & 36.369 & 2.728 & 2.687 & 0.536 & 36.505 & 2.288 & 2.275 & 0.474 & 36.081 & 2.780 & 2.761 & 0.587 \\
\hline Median household size & 2.573 & 0.198 & 0.193 & 0.047 & 2.653 & 0.176 & 0.171 & 0.054 & 2.538 & 0.208 & 0.207 & 0.041 \\
\hline Building permits $^{6}$ & 6,086 & 11,771 & 7,831 & 8,821 & 10,349 & 14,720 & 8,191 & 12,319 & 2,246 & 2,764 & 2,213 & 1,703 \\
\hline Change of building permits & -0.030 & 0.174 & 0.021 & 0.173 & -0.021 & 0.250 & 0.031 & 0.249 & -0.035 & 0.112 & 0.013 & 0.111 \\
\hline $\begin{array}{l}\text { Ratio of top } 10 \% \text { housing units } \\
\text { sold to median housing units sold }\end{array}$ & 1.308 & 2.057 & 1.501 & 1.415 & 0.504 & 1.085 & 0.486 & 0.974 & 2.505 & 2.623 & 1.942 & 1.796 \\
\hline $\begin{array}{l}\text { Ratio of high-end rental units to } \\
\text { high-end owner-occupied units }\end{array}$ & 2.472 & 3.816 & 2.322 & 3.037 & 1.568 & 0.895 & 0.630 & 0.646 & 3.245 & 4.287 & 2.755 & 3.321 \\
\hline D-index (Asian) & 0.296 & 0.093 & 0.093 & 0.000 & 0.332 & 0.100 & 0.102 & 0.000 & 0.296 & 0.083 & 0.084 & 0.000 \\
\hline D-index (Black) & 0.542 & 0.146 & 0.147 & 0.000 & 0.565 & 0.129 & 0.131 & 0.000 & 0.504 & 0.157 & 0.160 & 0.000 \\
\hline Median household income ${ }^{7}$ & 50,054 & 8,654 & 7,974 & 3,444 & 57,705 & 8,848 & 8,023 & 4,000 & 45,330 & 4,979 & 4,104 & 2,911 \\
\hline $\begin{array}{l}\text { Ratio of top } 10 \% \text { income to median } \\
\text { income }\end{array}$ & 2.594 & 0.270 & 0.181 & 0.201 & 2.665 & 0.324 & 0.222 & 0.240 & 2.530 & 0.239 & 0.159 & 0.181 \\
\hline
\end{tabular}

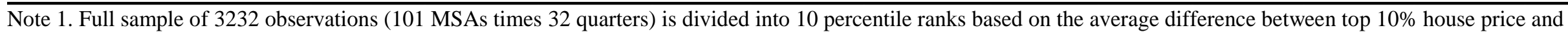

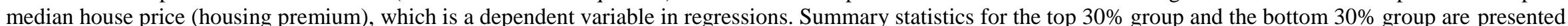

2. Over MSAs

3. Over time

4. 5. 6. 7. Log of these variables are included in regressions 
Table 4 Regression for the Full Sample

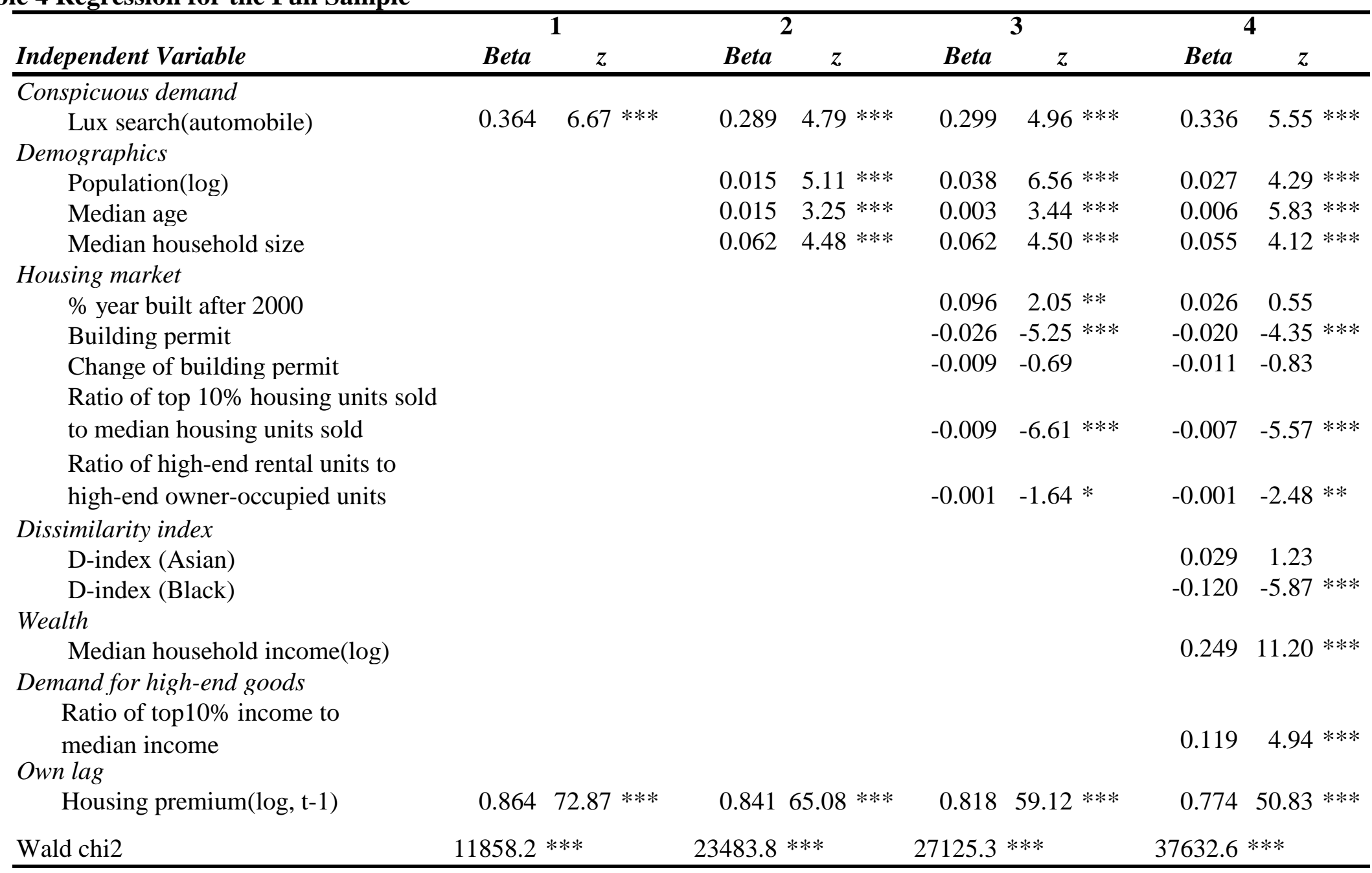

Note This table shows the results of the dynamic panel system GMM regressions for the full sample for the entire study period from 2004-2011. In this table, a dependent variable is the log of housing premium and the main independent variable is the ratio of the brand search to the product search in the automobile category. The first model contains only the lagged housing premium and the main independent variable, the second model also includes controls for basic demographics, the third column adds housing market condition control variables, and the fourth model is most comprehensive including dissimilarity indices, wealth, and high-end goods demand control variables, too. $* *$ indicates significance at the $1 \%$ level, $* *$ indicates significance at the $5 \%$ level, and * indicates significance at the $10 \%$ level. 


\section{Table 5 Regression for the sub samples}

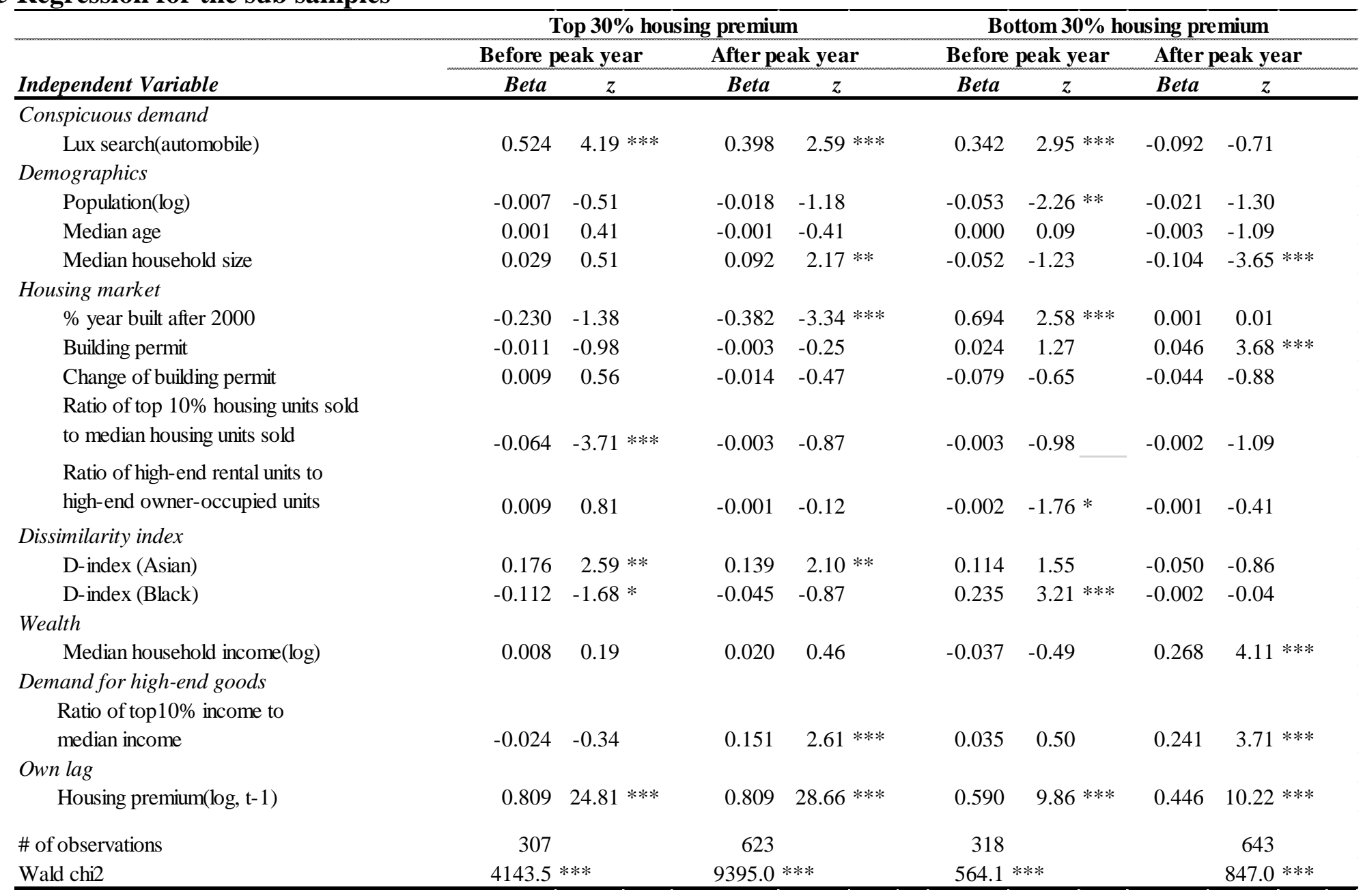

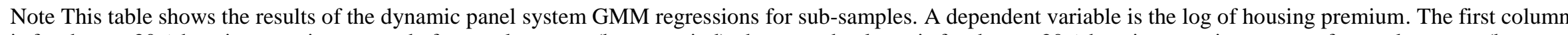
is for the top 30\% housing premium group before peak quarter (boom period), the second column is for the top 30\% housing premium group after peak quarter (bust period), the third column is for the bottom $30 \%$ housing premium group during the boom period, and the fourth column is for the bottom $30 \%$ housing premium group

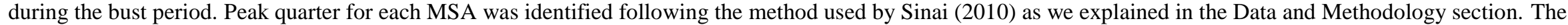
main independent variable is the ratio of the brand search to the product search in the automobile category. $* * *$ indicates significance at the $1 \%$ level, $* *$ indicates significance at the $5 \%$ level, and * indicates significance at the $10 \%$ level. 
Table 6 Regressions with external demand control

\begin{tabular}{|c|c|c|c|c|}
\hline \multirow[b]{2}{*}{ Independent Variable } & \multicolumn{2}{|c|}{1} & \multicolumn{2}{|c|}{2} \\
\hline & Beta & $z$ & Beta & $z$ \\
\hline \multicolumn{5}{|l|}{ Conspicuous demand } \\
\hline Lux search(automobile) & 0.522 & $5.85 * * *$ & 0.352 & $5.48 * * *$ \\
\hline \multicolumn{5}{|l|}{ External demand } \\
\hline Vacation home ratio & 0.007 & $4.46 * * *$ & & \\
\hline Vacation home ratio $\mathrm{x}$ Lux search & -0.017 & $-2.09 * *$ & & \\
\hline Overseas visitors & & & 0.144 & $2.99 * * *$ \\
\hline Overseas visitors $\mathrm{x}$ Lux search & & & -0.306 & $-2.34 * *$ \\
\hline Control variables & \multicolumn{2}{|l|}{ INCLUDED } & \multicolumn{2}{|l|}{ INCLUDED } \\
\hline Wald chi2 & \multicolumn{2}{|c|}{$41764.0 * * *$} & \multicolumn{2}{|c|}{$40075.1 * * *$} \\
\hline
\end{tabular}

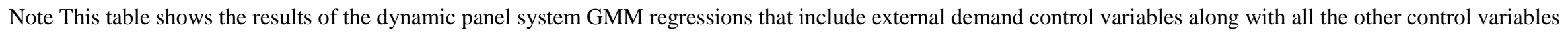
(demographics, housing market, dissimilarity index, wealth, demand for high-end goods, and serial correlation control variables). A dependent variable is the log of housing premium. The first column includes vacation home ratio and the interaction term between vacation home ratio and conspicuous demand variable. The second column includes the overseas visitors and the interaction term between overseas visitors and conspicuous demand variable. All control variables are included in both models, although not shown for presentation purpose. $* * *$ indicates significance at the $1 \%$ level and $* *$ indicates significance at the $5 \%$ level. 


\section{Appendix A measures of conspicuous demand}

To quantify the degree of conspicuous demand in each MSA for each quarter, we generate two lists: keywords for the product search and keywords for the brand search. We first define the major industries associated with luxury consumption. Following Uche (2007) and Chevalier and Mazzalovo (2008), we include four industries, "Automobiles", "Fashion-Leather", "Watches-Jewelry" and "Cosmetics-Perfume". Within each industry, we generate the keywords of product search. For instance, keywords of product search for Automobile industry is "car" and "cars". For other industries, we define their products based on the information from the websites of major brands. For the "Watches-Jewelry" industry, there is a long list of products such as watches, jewelry, rings, diamonds, earrings, necklaces, bracelets, pendants, and so on.

Then, we define the luxury brands within each industry based on the price of the products, company sales, and brand reputation. First, to generate the list of luxury car brands for the "Automobiles" industry, we compare two lists: Yamawaki (2002), Strach and Andre (2006), and Forbes “world's most expensive cars" list. ${ }^{24}$ Second, as suggested by Aït-Sahalia, Parker, and Yogo (2004), we select five most luxurious brands (top luxury brands) for the "Fashion-Leather" industry following the analyses from Morgan Stanley and Merrill Lynch. They include Saks, Tiffany, Bulgari, Gucci, Hermes and LVMH. Since LVMH produces multiple brands, we include all of them in the list of luxury brands, including Louis Vuitton, Celine, Loewe, Berluti, and Kenzo (List 1). In addition, we include other popular luxury brands for the "Fashion-Leather" industry and

\footnotetext{
${ }^{24}$ http://www.forbes.com/2010/02/01/porsche-bugatti-expensive-lifestyle-vehicles-cars-lamborghini.html
} 
divide them into two lists (List 2 and 3 ) by the price information provided on their websites (List 2 is more expensive than List 3). Finally, for the "Watches-Jewelry" and "Cosmetics-Perfume" industries, we select the top luxury brands based on the Merrill Lynch Lifestyle Index and Luxury Institute Wealth Report (List 1). Again, we add other popular luxury brands and group them by the price range (List 2 and 3).

If one brand produces products in multiple industries, the keywords for brand searches combine the brand name with the product name to avoid the additional counts of searches related with other products. For instance, in the "Watches-Jewelry" industry, the brand search for Bulgari is "Bulgari watches" and "Bulgari Jewelry" instead of "Bulgari". Table A shows the lists of the product search and luxury brand search. 


\section{Table A List of the product and brand searches}

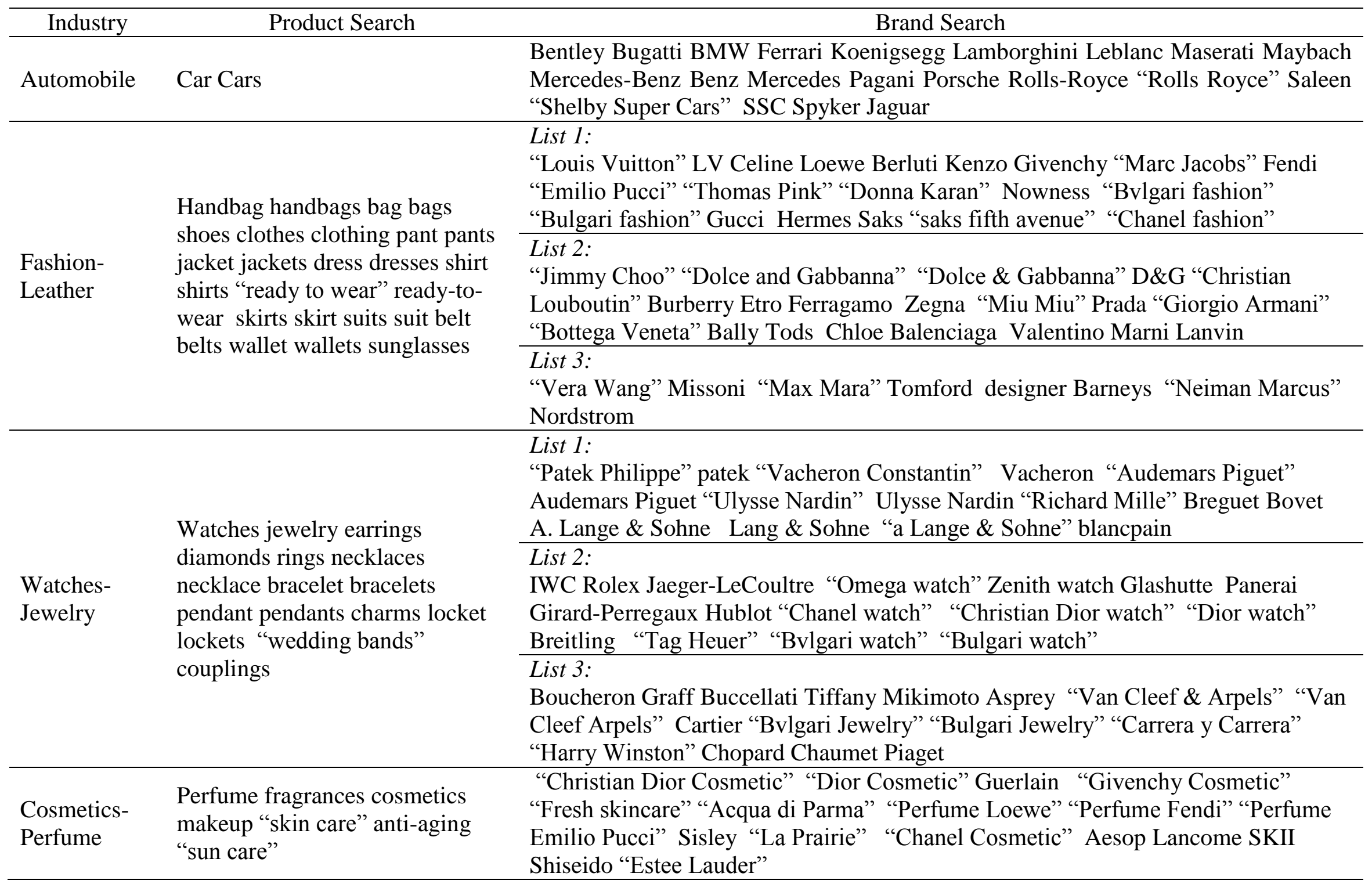




\section{Appendix B List of MSAs in high-premium and low-premium sub-samples}

\begin{tabular}{|c|c|c|c|}
\hline \multirow{2}{*}{$\begin{array}{c}\text { Top 30\% housing premium MSAs } \\
\text { (Descending order) }\end{array}$} & \multicolumn{3}{|c|}{ Bottom 30\% housing premium MSAs } \\
\hline & Average Premium & (Ascending order) & Average Premium \\
\hline Santa Barbara-Santa Maria-Goleta, CA & 733,914 & Rockford, IL & 80,029 \\
\hline Salinas, CA & 513,707 & Youngstown-Warren-Boardman, OH-PA & 82,723 \\
\hline San Francisco-Oakland-Fremont, CA & 490,337 & Davenport-Moline-Rock Island, IA-IL & 91,887 \\
\hline Los Angeles-Long Beach-Santa Ana, CA & 448,384 & Sherman-Denison, TX & 94,186 \\
\hline New York-Northern New Jersey-Long Island, NY-NJ-PA & 419,412 & Green Bay, WI & 98,053 \\
\hline Honolulu, HI & 399,380 & Billings, MT & 98,336 \\
\hline San Diego-Carlsbad-San Marcos, CA & 379,318 & El Paso, TX & 100,340 \\
\hline Boston-Cambridge-Quincy, MA-NH & 335,179 & Corpus Christi, TX & 104,311 \\
\hline Washington-Arlington-Alexandria, DC-VA-MD-WV & 307,590 & Lincoln, NE & 105,253 \\
\hline Miami-Fort Lauderdale-Pompano Beach, FL & 295,312 & Indianapolis-Carmel, IN & 105,282 \\
\hline Charleston-North Charleston-Summerville, SC & 288,144 & Springfield, MO & 105,523 \\
\hline Seattle-Tacoma-Bellevue, WA & 279,127 & Erie, PA & 107,263 \\
\hline Baltimore-Towson, MD & 253,192 & Missoula, MT & 110,046 \\
\hline Cape Coral-Fort Myers, FL & 247,116 & Champaign-Urbana, IL & 112,408 \\
\hline Chicago-Joliet-Naperville, IL-IN-WI & 244,009 & Grand Rapids-Wyoming, MI & 112,901 \\
\hline Reno-Sparks, NV & 224,101 & Yuma, AZ & 113,338 \\
\hline Philadelphia-Camden-Wilmington, PA-NJ-DE-MD & 220,042 & Toledo, $\mathrm{OH}$ & 116,011 \\
\hline Denver-Aurora-Broomfield, CO & 215,045 & Dayton, $\mathrm{OH}$ & 117,125 \\
\hline Sacramento--Arden-Arcade--Roseville, CA & 210,869 & San Antonio-New Braunfels, TX & 118,909 \\
\hline Atlanta-Sandy Springs-Marietta, GA & 210,673 & Buffalo-Niagara Falls, NY & 119,888 \\
\hline Charlotte-Gastonia-Rock Hill, NC-SC & 207,017 & Albuquerque, NM & 121,378 \\
\hline Phoenix-Mesa-Glendale, AZ & 203,857 & Duluth, MN-WI & 121,680 \\
\hline Panama City-Lynn Haven-Panama City Beach, FL & 199,552 & Peoria, IL & 122,899 \\
\hline Raleigh-Cary, NC & 197,999 & Salisbury, MD & 123,682 \\
\hline Minneapolis-St. Paul-Bloomington, MN-WI & 193,267 & Boise City-Nampa, ID & 124,795 \\
\hline Portland-Vancouver-Hillsboro, OR-WA & 191,395 & Grand Junction, CO & 125,079 \\
\hline Richmond, VA & 190,731 & Omaha-Council Bluffs, NE-IA & 126,111 \\
\hline Hartford-West Hartford-East Hartford, CT & 190,647 & Augusta-Richmond County, GA-SC & 127,261 \\
\hline Las Vegas-Paradise, NV & 184,352 & Columbia, SC & 128,449 \\
\hline Nashville-Davidson--Murfreesboro--Franklin, TN & 184,198 & Kansas City, MO-KS & 128,672 \\
\hline & & Bakersfield-Delano, CA & 130,321 \\
\hline
\end{tabular}




\section{Appendix C Regressions for the full sample for all luxury product categories}

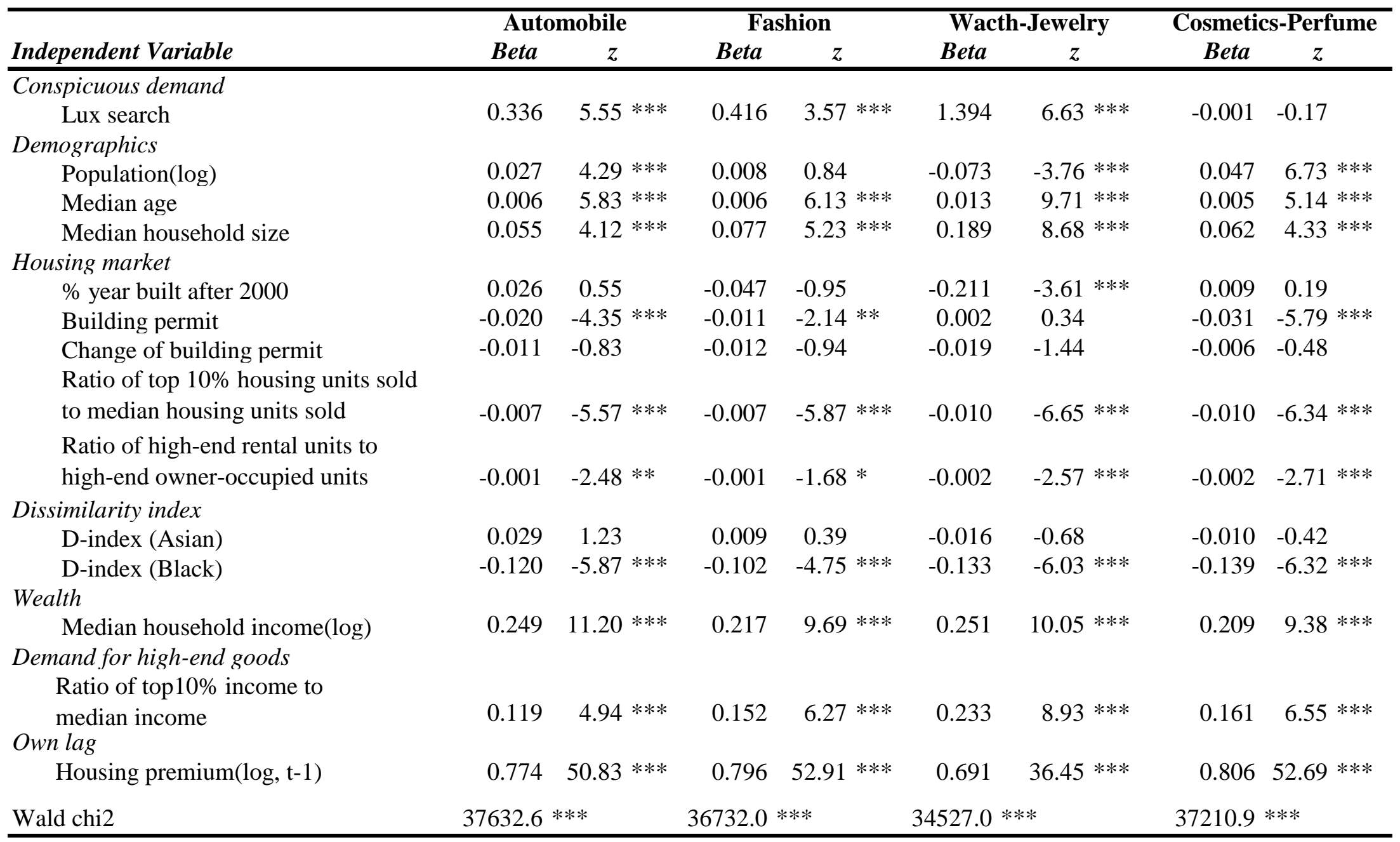

Note This table shows the results of the dynamic panel system GMM regressions for the full sample during the entire study period from 2004-2011. A dependent variable is the log of housing premium. Four models use different main independent variables, the ratio of brand search to product search for automobile category, fashion-leather category, watch-jewelry category, and cosmetics-perfume category. *** indicates significance at the $1 \%$ level, ** indicates significance at the $5 \%$ level, and $*$ indicates significance at the $10 \%$ level. 


\section{Appendix D}

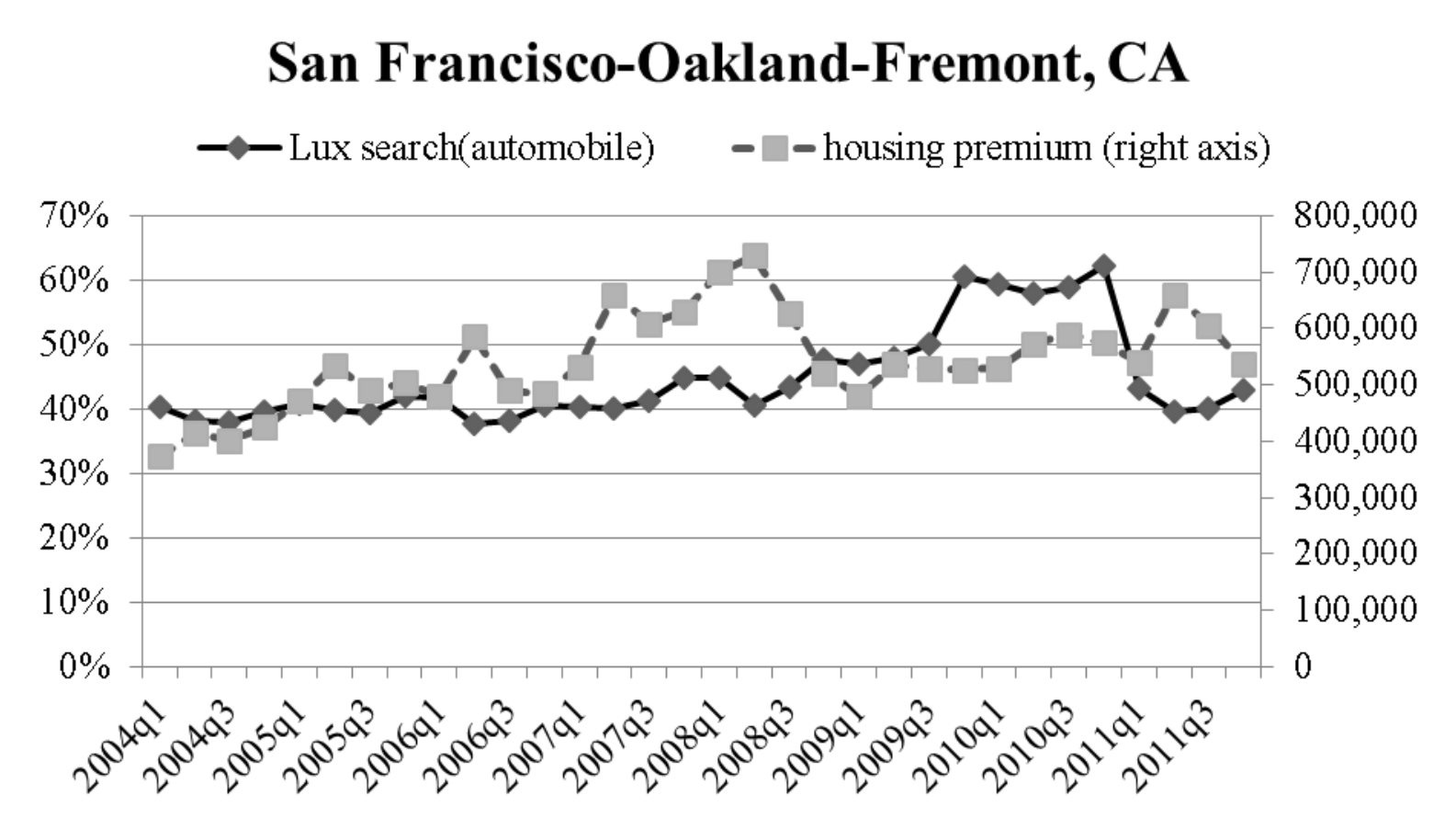

